\title{
Effect of dietary protein and genetic line of Litopenaeus vannamei on its
}

\author{
hepatopancreatic microbiota
}

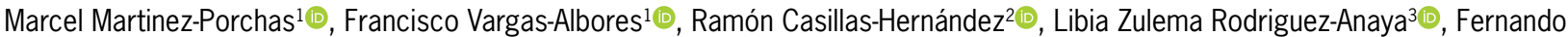

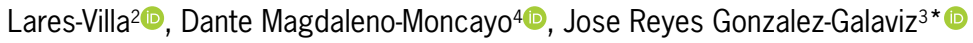

${ }^{1}$ Centro de Investigación en Alimentación y Desarrollo A.C., Carretera Gustavo Enrique Astiazarán Rosas, no. 46, Col. La Victoria - C.P. 83304 - Hermosillo, Sonora - Mexico. Instituto Tecnológico de Sonora - Depto. de Ciencias Agronómicas y Veterinarias - Ciudad Obregón, Sonora Mexico.

${ }^{3}$ CONACYT - Instituto Tecnológico de Sonora, Calle 5 de Febrero 818 Sur, Colonia Centro - C.P. 85000 - Ciudad Obregón, Sonora - Mexico.

${ }^{4}$ Centro de Investigación Científica y de Educación Superior de Ensenada - Depto. de Innovación Biomédica, Carretera Ensenada, Tijuana no. 3918 - Zona Playitas - C.P. 22860 Ensenada, B.C - México.

*Corresponding author <jose.gonzalez@itson.edu.mx>

Edited by: Antonio Faciola

Received April 13, 2020

Accepted June 15, 2020
ABSTRACT: Host genetics and diet can exert an influence on microbiota and, therefore, on feeding efficiency. This study evaluated the effect of genetic line (fast-growth and high-resistance) in Pacific white shrimp (Litopenaeus vannamei) on the hepatopancreatic microbiota and its association with the feeding efficiency in shrimp fed with diets containing different protein sources. Shrimp $(2.08 \pm 0.06 \mathrm{~g})$ from each genetic line were fed for 36 days with two dietary treatments (animal and vegetable protein). Each of the four groups was sampled, and the hepatopancreatic metagenome was amplified using specific primers for the variable V4 region of the $16 \mathrm{~S}$ rRNA gene. The PCR product was sequenced on the MiSeq platform. Nineteen bacterial phyla were detected, of which Proteobacteria was the most abundant (51.0 - 72.5\%), Bacteroidetes (3.6 - 23.3\%), Firmicutes (4.2 - $13.7 \%$ ), Actinobacteria (1.9-12.1\%), and Planctomycetes (1.3 - 9.5\%). Diet was the most influential factor in the taxonomic composition of the microbiota, while genetic line was not a strong influential factor. The results suggest that the taxonomic profile of the bacteria colonizing shrimp hepatopancreas was determined by the diet consumed, similar to what occurs in the intestine. Shrimp in the fast-growth line had greater feeding efficiency regardless of the diet supplied. Finally, the results suggest that Proteobacteria influenced $(p<0.05)$ the feeding efficiency of shrimp fed with a vegetable diet. Nevertheless, further studies are required to explore how shrimp genetic line-diet interaction influences microbiota for probiotic development and functional food formulation for farmed shrimp according to the genetic line.

Keywords: shrimp genetic line, fishmeal replacement, productive response, feeding efficiency

\section{Introduction}

Litopenaeus vannamei is one of the most economically important shrimp in aquaculture worldwide, accounting for $53 \%$ of the total production of crustaceans (FAO, 2018). However, the sustainability of shrimp farming depends upon the production of postlarvae with genetic traits of economic interest and the availability of food (Gong et al., 2012).

In Mexico, shrimp postlarvae with fast-growing and high-resistance characteristics are produced for the national aquaculture (Castillo-Juárez et al., 2015; Mendoza-Cano et al., 2014). Fishmeal and fish oil are the main ingredients for the formulated foods intended for aquaculture; however, these depend upon limited resources while posing a risk of overexploitation by fisheries (FAO, 2018). Furthermore, feeding represents 50 to $60 \%$ of the total cost of production (Dai et al., 2017). Therefore, soybean protein has become the most common substitute for fishmeal (Naylor et al., 2009).

Shrimp genetic line and diets can influence growth performance (Gonzalez-Galaviz et al., 2020). Moreover, several factors influence the feeding efficiency of shrimp (Porchas-Cornejo et al., 2011; Tacon et al., 2002; Wyban et al., 1995); however, special attention has been directed towards the contribution of the gut microbiota. This microbiota plays an important role in the host's nutritional performance (Garibay-Valdez et al., 2019; Rungrassamee et al., 2014; Tzuc et al., 2014), and is affected mainly by biological and environmental factors (Brestoff and Artis, 2013; Cornejo-Granados et al., 2018). Nevertheless, the underlying mechanisms affecting the microbial community by diverse factors related to host physiology remain as pending signatures (Duan et al., 2017; Huang et al., 2016; Ringø et al., 2016).

The genetic improvement of traits with economic importance has been developed by the use of selective breeding (Gjedrem and Rye, 2018). Selective breeding in shrimp has been carried out with the emphasis on improving growth (De Donato et al., 2005; Lu et al., 2016; Luan et al., 2015) and resistance to pathogens (Gitterle et al., 2006; Ødegård et al., 2011). However, there is no information to substantiate if these conditions also produce changes in the composition of gut microbiota or whether there is evidence to indicate that the type of food consumed by shrimp shapes its gut microbiota (Cornejo-Granados et al., 2018; GaribayValdez et al., 2019).

The objective of this work was to determine if the genetic line of $L$. vannamei influences the composition of shrimp microbiota and its association with feeding efficiency when shrimp are fed with diets containing protein of different origin. 


\section{Materials and Methods}

\section{Ethics Statement}

The authors confirm that ethical policies, as noted on the journal guidelines page, have been adhered to. Animal ethics approval was not required for crustacean species. This study was conducted in accordance with standard practices.

\section{Diet formulation}

Two experimental diets containing animal or vegetable protein were formulated according to specifications reported on by López-Vela et al. (2014). The first diet was made with fishmeal as the main protein source, while the second incorporated a mixture of soy protein and $6 \%$ of fish raw materials (fishmeal and fish oil) as an attractant (Table 1). Proximate composition analysis of these diets was carried out in accordance with official methods (AOAC, 2016) (Table 1).

Table 1 - Formulation and proximate composition of diets containing vegetable or animal products as the main protein source.

\begin{tabular}{lrr}
\hline \multirow{2}{*}{ Ingredients } & \multicolumn{2}{c}{ Content $\left(\mathrm{g} \mathrm{kg}^{-1}\right.$ diet) } \\
\cline { 2 - 3 } & Animal & Vegetable \\
\hline Fishmeal $^{1}$ & 247.56 & 34.77 \\
Soy protein extract $^{2}$ & 0.00 & 312.92 \\
Soy flour $^{3}$ & 247.56 & 208.62 \\
Wheat flour $^{4}$ & 184.43 & 139.08 \\
Corn starch $^{5}$ & 168.96 & 190.08 \\
Fish oil $^{6}$ & 64.23 & 26.22 \\
Soy lecithin & & 36.20 \\
Minerals $^{8}$ & 33.40 & 9.25 \\
Vitamins $^{9}$ & 8.53 & 9.25 \\
Alginic acid $^{10}$ & 8.53 & 18.49 \\
Ash $^{11}$ & 17.06 & 9.44 \\
Cellulose $^{12}$ & 17.49 & 5.67 \\
Antioxidants $^{13}$ & 2.23 & 0.01 \\
\hline Proximal comp & 0.01 &
\end{tabular}

Proximal composition (g kg-1 dry matter, except moisture)

$\begin{array}{lcc}\text { Moisture } & 28.5 \pm 0.5 & 12.2 \pm 0.8 \\ \text { Crude protein } & 321.2 \pm 1.2 & 356.3 \pm 0.7 \\ \text { Ethereal extract } & 58.4 \pm 0.5 & 66.5 \pm 0.0 \\ \text { Crude fiber } & 2.3 \pm 0.6 & 11.7 \pm 0.6 \\ \text { Ash } & 108.6 \pm 0.3 & 55.9 \pm 0.3 \\ \text { Nitrogen-free extracts } & 509.4 & 509.7 \\ \text { Brute energy (Kcal) } & 4.33 \pm 0.002 & 4.64 \pm 0.004 \\ \text { Nitrogen } & 51.4 \pm 0.2 & 57.0 \pm 0.1\end{array}$

${ }^{1}$ Whole sardine meal $(72.95 \%$ crude protein (CP), $6.38 \%$ lipid). PIASA (La Paz, Baja California Sur, México); ${ }^{2}$ Soy protein extract (SPE) $(64.70 \%$ CP, $1.13 \%$ lipid). PIASA (La Paz, Baja California Sur, México); ${ }^{3}$ Soy flour (50.95 \% CP, 1.17 \% lipid). PIASA (La Paz, Baja California Sur, México); ${ }^{4}$ Wheat flour (13.38 \% CP, 0.4 \% lipid). PIASA (La Paz, Baja California Sur, México); ${ }^{5}$ Corn starch (0.3\% CP, $0.1 \%$ lipid). Unilever de México, S. de R.L. de C.V. (Tultitlán, Estado de México, México); ${ }^{6}$ Sardine oil. PIASA (La Paz, Baja California Sur, México); ${ }^{7}$ Soy lecithin. PIASA (La Paz, Baja California Sur, México); ${ }^{8}$ Minerals. PIASA (La Paz, Baja California Sur, México); ${ }^{2}$ itamins. PIASA (La Paz, Baja California Sur, México); ${ }^{10}$ Alginic acid. Sigma-Aldrich Corp. 180947 (St. Louis, MO, USA); ${ }^{11}$ Ash. Sigma-Aldrich Corp. 180947 (St. Louis, MO, USA). D3877; ${ }^{12}$ Cellulose. Sigma-Aldrich Corp. C6288 (St. Louis, MO, USA); ${ }^{13 B}$ Butylated hydroxytoluene (BHT). Sigma-Aldrich Corp. 180947 (St. Louis, MO, USA).

\section{Experimental shrimp}

Approximately 2,000 Litopenaeus vannamei postlarvae $\left(\mathrm{PL}_{12}-\mathrm{PL}_{14}\right)$ from two genetic lines were collected. The fast-growth line (FG) was obtained from a hatchery located at Baja California Sur, Mexico, whereas the high-resistance line (HR) was obtained from a hatchery located in Sonora, Mexico. Both genetic lines were determined as being free of specific pathogens according to the diseases reported by the World Organization for Animal Health (OIE). The postlarvae were acclimated in 1,500 L tanks containing seawater under controlled conditions (temperature $30 \pm 0.5{ }^{\circ} \mathrm{C}$, dissolved oxygen $\geq 4 \mathrm{mg} \mathrm{L}^{-1}$, salinity $37 \mathrm{mg} \mathrm{L}^{-1}, \mathrm{pH} \geq 7$, and $12 \mathrm{~h}$ photoperiod). A formulated diet containing $32 \%$ of crude protein was used to feed shrimp until reaching an individual average weight of $2.08 \pm 0.06 \mathrm{~g}$. Before starting the bioassay, the hepatopancreas from three organisms of each genetic line was dissected. These samples were considered as the control for each genetic line and were preserved in a $2 \mathrm{~mL}$ centrifuge tube containing $1.5 \mathrm{~mL}$ of phosphate buffer saline (PBS: $0.137 \mathrm{M} \mathrm{NaCl}, 0.0027 \mathrm{M} \mathrm{KCl}, 0.01$ $\mathrm{M} \mathrm{Na}_{2} \mathrm{HPO}_{4}$ and $\mathrm{KH}_{2} \mathrm{PO}_{4}$ ), then stored at $-80{ }^{\circ} \mathrm{C}$, until further analysis.

\section{Experimental design}

After acclimatization, shrimp from each genetic line (FG and $\mathrm{HR}$ ) were placed into six rectangular tanks of $40 \mathrm{~L}(50 \times 30 \times 30 \mathrm{~cm})$ at a density of 10 shrimp per tank (12 tanks in total). Three tanks from each group were used as replicas for testing each formulated diet based on vegetable or animal protein. The bioassay lasted 36 days, during which the organisms were fed ad libitum with an initial portion of $10 \%-12 \%$ of their biomass distributed three times a day $(8 \mathrm{~h} 00,13 \mathrm{~h} 00$ and 16h00), and adjusted daily according to the presence or absence of residual food. The uneaten food, feces, molts, and dead shrimp were removed daily.

The productive response was calculated according to the equations reported in our previous study (GonzalezGalaviz et al., 2020): Final total weight (FWT) $=\Sigma$ Final Individual Weight / Final Number of Shrimp; Survival $(\%)=100 *$ (Final Number of Shrimp / Initial Number of Shrimp); Final biomass $=$ FWT $*$ Final Number of Shrimp; Feed Intake $=$ Feed Input (g, dry weight) - Feed collected ( $g$, dry weight); and Factor Conversion Rate $($ FCR $)=$ Feed Intake / Final biomass. Feeding efficiency was determined according to FCR. Hepatopancreases were collected from three organisms of each treatment, then placed in PBS and stored at $-80{ }^{\circ} \mathrm{C}$ until genomic DNA extraction.

\section{DNA extraction, library preparation and sequencing}

Shrimp hepatopancreases before (control) and after the trial were pooled and homogenized, and the FastDNA ${ }^{\mathrm{TM}}$ Spin Kit for Soil was used to extract whole genomic DNA according to the manufacturer's 
instructions as was suggested by Le et al. (2020). The extracted DNA was analyzed by spectrophotometry to ensure its concentration and purity. DNA integrity was determined by electrophoresis in $1 \%$ agarose gel.

Bacterial 16S rRNA genes were amplified with primers targeting the V4 region. Each sample was amplified using the primers $515 \mathrm{~F}$ 5'-GTGCCAGCMGCCGCGGTAA-3' and 806R 5'-GGACTACHVGGGTWTCTAAT-3' (Caporaso et al., 2011) with the adaptor sequence, sample-specific eight-base, pad and linker (Kozich et al., 2013). The PCR mixtures contained 20 ng of DNA, 1X buffer My Taq (0.32 mM dNTP's, $1.5 \mathrm{mM} \mathrm{MgCl2}$ ), $0.3 \mathrm{mM}$ of each primer, and $0.625 \mathrm{U}$ My Taq DNA polymerase according to the mix suggested by Le et al. (2020). The thermocycling conditions were set as follows: $95^{\circ} \mathrm{C}$ for $3 \mathrm{~min}$, followed by 32 cycles of $95^{\circ} \mathrm{C} / 20 \mathrm{sec}, 55^{\circ} \mathrm{C} / 15$ sec, $72^{\circ} \mathrm{C} / 5 \mathrm{~min}$, and a final extension of $72^{\circ} \mathrm{C}$ for 7 $\min$.

The PCR products were purified using the SequalPrep plate normalization kit, quantified and pooled in equimolar concentrations. Each sample and the final library concentrations were quantified using the Qubit dsDNA HS kit. The library was mixed with the PhiX control library, and the sequencing process carried out in the MiSeq platform using the Miseq Reagent Kit v2.

The quantity and quality of raw reads (R1 and R2) were analyzed with the FastQC software control tool (Wingett and Andrews, 2018) and reads sizing 300 bases were obtained. A standard QIIME2 pipeline (Bolyen et al., 2019) was used to filter low quality reads, merging R1 and $\mathrm{R} 2$, denoise the reads and discard chimeras through DADA2 (Callahan et al., 2016). Sequencing depth used to calculate the alpha diversity metrics was set at 10,000 reads per sample.

\section{Statistical analyses}

Alpha diversity and beta diversity analyses based on weighted UniFrac phylogenetic distances and taxonomic classification were carried out in QIIME2 whereas comparison analyses, analysis of similarity and R-squared tests were carried out using the STAMP software package (statistical analysis of taxonomic and functional profiles) (Parks et al., 2014). Multidimensional scaling to explore and visualize similarities or dissimilarities between bacterial profiles was carried out by means of a Principal Coordinate Analysis (PCoA) in QIIME2. Statistical analyses of alpha diversity were calculated by one-way analysis of variance. Production parameters were analyzed by a two-way analysis of variance (after homoscedasticity and normality tests). If any significance was observed, Tukey's multiple comparison test was applied to determine the differences between treatment means. To determine association with feeding efficiency, microbial taxa with a relative abundance greater than $0.01 \%$ were compared between shrimp genetic lines (using $t$ test) as described by Li et al. (2019). Significance was set at a probability level of $p<0.05$ (95\% confidence). Probability values between 0.05 and 0.10 were considered a trend.

\section{Results}

The productive response of the FG genetic line was better $(p<0.05)$ when shrimp were fed the animal diet, while the productive response of shrimp from the HR genetic line did not differ $(p>0.05)$ between dietary treatments. According to FCR values, shrimp from the FG genetic line had a higher $(p<0.05)$ feeding efficiency with low FCR values (L-FCR) and shrimp from the HR genetic line had a lower feeding efficiency with high FCR values (H-FCR). The statistical analysis indicated that genetic line-diet interaction influenced $(p<0.05)$ final total weight, biomass and survival (Table 2).

Sequencing results revealed an average of 34,228 $(12,365-53,174)$ non-chimeric reads per sample resulting after filtering, denoising, and merging pipeline.

As regards shrimp microbiota, 19 phyla were detected. Five only resulted in being the most abundant (> $1.5 \%$ ) regardless of genetic line and diet intake. Proteobacteria (51.0-72.5 \%), Bacteroidetes (3.6-23.3 \%), Firmicutes (4.2-13.7 \%), Actinobacteria (1.9-12.1 \%), and Planctomycetes (1.3-9.5 \%) (Figure 1).

In general, microbiota results revealed that the genetic line was not a strong influential factor; 143 families were detected and only five of these (Nocardiaceae, Paenibaillae, Psychromonadacae, Stappiceae, and Streptococcaceae) registered differences $(p<0.05)$ between genetic lines. Moreover, R-squared

Table 2 - Production performance of fast-growth (FG) and high-resistance (HR) shrimp genetic lines fed with diets containing vegetable or animal protein as the main source. P-values consider both factors.

\begin{tabular}{|c|c|c|c|c|c|c|c|c|}
\hline \multirow{2}{*}{ ITEM } & \multicolumn{2}{|c|}{$\mathrm{FG}$} & \multicolumn{2}{|c|}{ HR } & \multirow{2}{*}{ Pooled SE } & \multicolumn{3}{|c|}{$p$-value } \\
\hline & Animal & Vegetable & Animal & Vegetable & & Genetic line & Diet & Genetic line - Die \\
\hline $\mathrm{FW}_{\mathrm{T}}(\mathrm{g})$ & $8.1^{\mathrm{a}}$ & $7.0^{\mathrm{b}}$ & $4.3^{a}$ & $4.4^{\mathrm{a}}$ & 0.17 & $<0.01$ & 0.01 & 0.01 \\
\hline Survival (\%) & $89.3^{a}$ & $77.3^{b}$ & $96.0^{a}$ & $97.3^{\mathrm{a}}$ & 2.08 & $<0.01$ & 0.03 & 0.01 \\
\hline Final biomass (g) & $72.8^{a}$ & $54.2^{\mathrm{b}}$ & $41.4^{\mathrm{a}}$ & $42.4^{\mathrm{a}}$ & 2.01 & $<0.01$ & $<0.01$ & $<0.01$ \\
\hline Feed Intake (g) & $130.2^{\mathrm{a}}$ & $95.1^{\mathrm{b}}$ & $82.9^{a}$ & $88.0^{a}$ & 3.43 & $<0.01$ & $<0.01$ & $<0.01$ \\
\hline FCR & $1.8^{\mathrm{a}}$ & $1.8^{\mathrm{a}}$ & $2.0^{\mathrm{a}}$ & $2.1^{\mathrm{a}}$ & 0.05 & $<0.01$ & 0.77 & 0.38 \\
\hline
\end{tabular}

Different superscript letters in the same row indicate significant differences at $p<0.05$; Pooled SE $=$ Pooled standard error. 


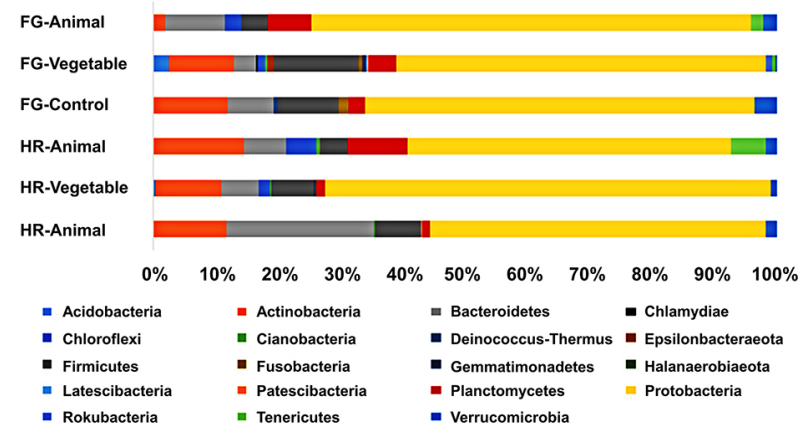

Figure 1 - The relative abundance of bacterial phyla detected in hepatopancreatic tissue of shrimp belonging to a fast-growth (FG) and high-resistance $(\mathrm{HR})$ genetic lines and fed with a control diet and diets containing protein of both vegetable and animal origin.

$\left(\mathrm{R}^{2}\right)$ analysis considering the abundance of each family between genetic lines registered a similitude of $70 \%$ for the taxonomic profile of microbiota (Figure 2). PCoA, considering only genetic lines, also revealed that both genetic lines tended to cluster together (Figure 3).

In contrast, the diet affected the microbiota composition. Tenericutes $\mid p=0.012 ; 0.00 \%$ vs $0.01-$ $0.62 \%)$ and Planctomycetes $(p=0.030 ; 0.35-2.65 \%$ vs $1.55-4.24 \%$ ) were favored in shrimp consuming the animal diet compared with the control and vegetable diets, while Acidobacteria $(p=0.022 ; 0.00 \%$ vs $0.22-$ $4.44 \%$ ) and Gemmatimonadetes ( $p=0.023 ; 0.00 \%$ vs 0.15-0.64 \%) were more abundant in shrimp fed with the vegetable diet. $\mathrm{R}^{2}$ measured at the family level revealed that the microbiota of shrimp fed with the animal diet showed the least similarity with those fed with the control $(40 \%)$, contrasting with the $67 \%$ registered between the control and vegetable diets (Figure 2). However, the greatest difference between microbiota profiles was detected when comparing shrimp consuming the animal diet with shrimp consuming the vegetable diet; the similarity between these two microbiotas was only about $3-13 \%$ (Table 3; Figure 3).

In terms of alpha diversity, fast-growth genetic line registered a higher $(p<0.05)$ Shannon index value of $5.66( \pm 1.05)$ compared with $4.33( \pm 0.69)$ for the highresistance genetic line. Additionally, according to the diet consumed, Shannon index values of $4.58( \pm 0.68)$, $5.21( \pm 1.48)$, and $4.49( \pm 0.78)$ were registered for shrimp consuming the control, vegetable, and animal diets, respectively; however no differences $(p>0.05)$ were registered.

According to the association between hepatopancreatic microbiota and feeding efficiency of two shrimp genetic lines fed with different protein sources, Proteobacteria influenced $(p<0.05)$ feeding efficiency when shrimp were fed with the vegetable diet, while Planctomycetes tended $(p=0.10)$ to influence feeding efficiency when shrimp were fed with the animal diet (Table 4).

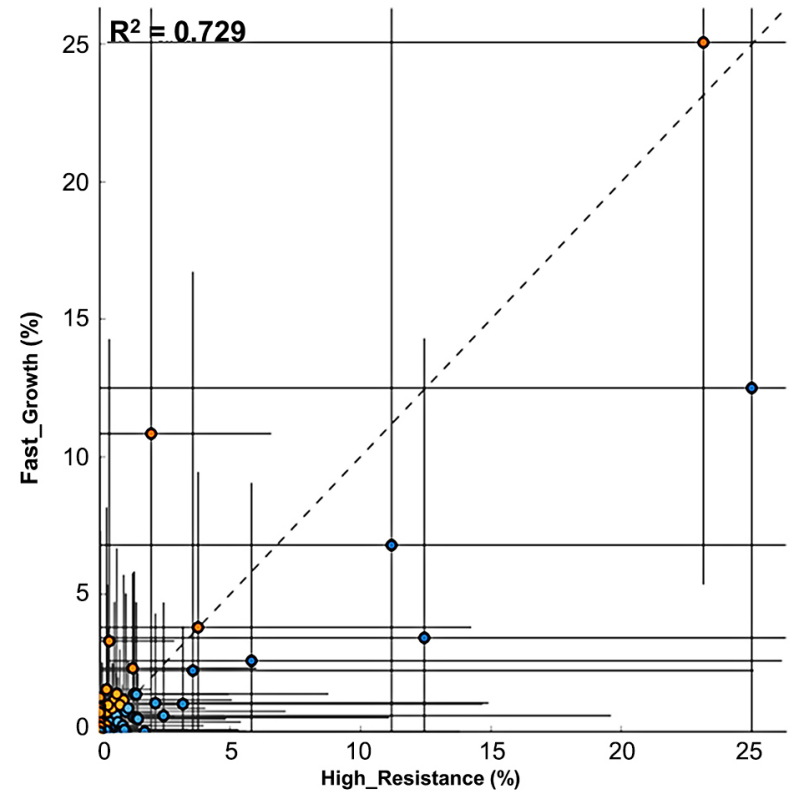

Figure 2 - Coefficient of determination $\left(R^{2}\right)$ between taxonomic profiles of microbiota detected in hepatopancreatic tissue of shrimp belonging to two different genetic lines (high-resistance and fast-growth lines).

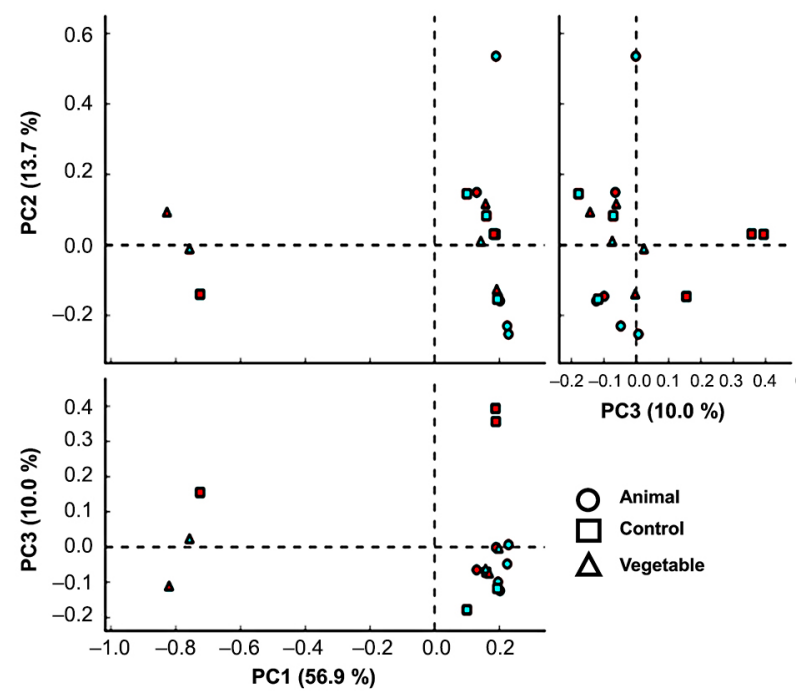

Figure 3 - Principal coordinate analysis of microbiota profile of the hepatopancreas of shrimp belonging to two genetic lines: a fastgrowth line (blue), and a high-resistance line (red).

\section{Discussion}

The anatomy of the digestive system of the shrimp consists of the stomach, the hepatopancreas and the intestine. However, it is in the hepatopancreas where over $60 \%$ of the digestive process of proteins is carried out (Tzuc et al., 2014; Silva et al., 2016). Results revealed that the bacterial composition in hepatopancreas was 
Table 3 - Comparison matrix between hepatopancreatic microbiota detected in high-resistance (HR) and fast-growth (FG) shrimp genetic lines fed with diets containing vegetable or animal protein as the main source. The Table shows a conditional format in descending sequence from high (1.00 or green) towards low similarity (0.03 or red).

\begin{tabular}{|c|c|c|c|c|c|c|}
\hline & HR-Control & HR-Animal & HR-Vegetable & FG-Control & FG-Animal & FG-Vegetable \\
\hline HR-Control & 1.00 & & & & & \\
\hline HR-Animal & 0.14 & 1.00 & & & & \\
\hline HR-Vegetable & 0.40 & 0.19 & 1.00 & & & \\
\hline FG-Control & 0.16 & 0.63 & 0.40 & 1.00 & & \\
\hline FG-Animal & 0.17 & 0.51 & 0.13 & 0.40 & 1.00 & \\
\hline FG-Vegetable & 0.40 & 0.04 & 0.67 & 0.14 & 0.03 & 1.00 \\
\hline
\end{tabular}

Table 4 - Association of relative abundance of differential microbial taxa with feeding efficiency (L-FCR: Higher feeding efficiency; H-FCR: Lower feeding efficiency) of fast-growth (FG) and highresistance (HR) shrimp genetic lines fed with different protein source.

\begin{tabular}{llrrr}
\hline \multirow{2}{*}{$\begin{array}{l}\text { Dietary } \\
\text { treatment }\end{array}$} & \multicolumn{1}{c}{ Phyla } & $\begin{array}{c}\text { Feeding efficiency } \\
\text { FG genetic line } \\
\text { (L-FCR) } \\
\text { Mean } \pm \text { SEM }\end{array}$ & $\begin{array}{c}\text { HRenetic line } \\
\text { (H-FCR) } \\
\text { Mean } \pm \text { SEM }\end{array}$ & \\
\hline Vegetable diet & & & \\
& & & & \\
& Actinobacteria & $12.8 \pm 4.8$ & $10.8 \pm 6.7$ & 0.87 \\
& Bacteroidetes & $5.0 \pm 1.3$ & $6.0 \pm 3.6$ & 0.81 \\
& Chloroflexi & $1.6 \pm 0.9$ & $1.7 \pm 1.4$ & 0.95 \\
& Firmicutes & $22.8 \pm 7.4$ & $5.9 \pm 3.5$ & 0.26 \\
& Planctomycetes & $5.8 \pm 0.7$ & $1.5 \pm 1.5$ & 0.12 \\
& Proteobacteria & $40.8 \pm 3.9$ & $72.5 \pm 4.2$ & 0.05 \\
\hline Animal diet & & & \\
& Actinobacteria & $5.9 \pm 2.3$ & $14.6 \pm 10.7$ & 0.44 \\
& Bacteroidetes & $9.9 \pm 1.8$ & $6.6 \pm 1.8$ & 0.17 \\
& Chloroflexi & $2.6 \pm 1.1$ & $5.0 \pm 4.3$ & 0.69 \\
& Firmicutes & $2.2 \pm 0.9$ & $4.5 \pm 0.9$ & 0.22 \\
& Planctomycetes & $7.0 \pm 3.1$ & $11.6 \pm 4.2$ & 0.10 \\
\hline & Proteobacteria & $68.2 \pm 6.2$ & $47.8 \pm 9.1$ & 0.31 \\
\hline$p<0.05$ indicates significant differences; SEM $=$ Standard error of mean.
\end{tabular}

similar to that of the intestine documented in other reports, where Proteobacteria, Bacteroidetes, Firmicutes, Tenericutes, Actinobacteria, and Planctomycetes are the dominant phyla (Cornejo-Granados et al., 2017; GaribayValdez et al., 2019).

Results obtained from this study suggest that the genetic line was not a determinant factor in shaping the shrimp's hepatopancreatic microbiota. Therefore, genetic differences between $\mathrm{HR}$ and FG shrimp may not be expressed as different microenvironmental conditions in the digestive tract (particularly in the hepatopancreatic zone), leading to the harboring of similar microbiota regardless of the shrimp genetic profile. Genetic lines for high-resistance to pathogens or better growth performance have been used for the last two decades (Gitterle et al., 2005) and a previous study suggested that the genetic profile of $L$. vannamei can be an important factor in gut bacterial composition
(Landsman et al., 2019). However, the results of this experiment indicate that neither enhanced resistance to pathogens nor better growth performance is associated with significant modifications in the shrimp microbiota, at least in the hepatopancreatic zone. Therefore, in the main, the genetic traits of shrimp may not be associated with their microbiota functions, but to intrinsic and improved features in their bioenergetics and immune response performance.

In contrast, the type of consumed diet seemed like a more determining factor in shaping this microbiota. In this regard, previous evidence has demonstrated that factors such as lifestyle, feeding habits, and probiotic usage, are perhaps the most influential factors on the taxonomic structure of the gut microbiota of penaeid shrimp (Cornejo-Granados et al., 2018; Garibay-Valdez et al., 2019; Vargas-Albores et al., 2017). Feed not only represents a nutrient source, but is also a factor that impacts the microbiota and therefore influences host health and metabolism (Serra et al., 2019). Thus, differences between animal and vegetable proteins could favor particular bacterial taxa; however, even if the role of microbiota in the hepatopancreatic zone is unclear, the strong similarity to the intestinal microbiota recorded in other experiments suggests similar functions (Gao et al., 2019).

Among the changes produced by the type of diet consumed, the phyla Tenericutes and Planctomycetes increased in shrimp supplied with the animal diet, while Acidobacteria and Gemmatimonadetes were favored with the vegetable diet. The underlying factors driving these changes are unclear; however, Rimoldi et al. (2018) argued that unlike vegetable sources of proteins, fishmeal is commonly rich in most essential amino acids and contain important amounts of water-soluble proteins that could drive the proliferation of certain bacterial groups. Rimoldi et al. (2018) replaced fishmeal with vegetable protein at a different level concluding that the ratio between vegetable and animal proteins proved to play a central role in determining microbiome profiles and the phyla Firmicutes and Proteobacteria were particularly discriminatory as regards diet type in trout. Plant ingredients favored a higher Firmicutes:Proteobacteria ratio than animal proteins. Desai et al. (2012) observed that 
the replacement of fishmeal with $30 \%$ of soybean meal in rainbow trout diets led to a reduction in Proteobacteria and an increase in Firmicutes. A contrasting pattern was observed in our results. The Firmicutes/Proteobacteria ratio was 0.11 and 0.06 for $\mathrm{HR}$ - and FG shrimp, respectively, and a correlation of -0.42 , suggesting that this ratio may favor shrimp growth; however, this has yet to be proved. Additionally, no clear pattern was detected to explain a potential contribution of certain taxonomic groups or a combination of these on the production response of shrimp.

According to the association between hepatopancreatic microbiota and feeding efficiency of shrimp from two genetic lines fed with different protein sources, Proteobacteria was more abundant $(p<0.05)$ in the HR genetic line compared to the FG genetic line when the shrimp were fed with the vegetable diet, suggesting an influence of this taxon on feeding efficiency. Moreover, microbiota did not influence $(p>$ 0.05) feeding efficiency when the shrimp were fed with animal diet. These results could be interesting, given that previous studies have determined indicator taxa for growth and resistance characteristics in rainbow trout (Brown et al., 2019; Chapagain et al., 2019). Furthermore, a study on Common Carp suggested that Proteobacteria, Bacteroidetes, and Firmicutes were related to the host's metabolic factors (Li et al., 2013). Moreover, Bacteroidetes (Prevotella) and Actinobacteria (Bifidobacterium) were determined as indicator taxa for the body weight of shrimp (Fan et al., 2019), which, this being the case, makes it necessary to further investigate how shrimp microbiota influence feeding efficiency. It could help to improve the shrimp feeding efficiency by reducing the amount of feed consumed without affecting production performance and decreasing the negative environmental effects caused by aquaculture.

Our results suggest that the genetic line was not as strong an influential factor as the type of diet consumed on shrimp hepatopancreatic microbiota. In addition, it was observed that the microbiota can influence feeding efficiency in shrimp. Nevertheless, the assay was carried out under controlled conditions in a short-term bioassay with genetic lines from two hatcheries and a few samples for metagenomic analysis. Therefore, these results are preliminary and it would be interesting to perform an assay on shrimp from different Mexican hatcheries that would consider a vegetable diet supplemented with essential amino acids and a long-term bioassay under commercial farming conditions augmented by wider sampling to determine how the pond environment and its biota can affect these results.

\section{Conclusion}

This microbiota may be more likely to be affected by the type of protein contained in the shrimp diet than its genetic line. Shrimp from the fast-growth line had a higher feeding efficiency regardless of the diet supplied.
Moreover, the results suggest that Proteobacteria influences the feeding efficiency of shrimp when shrimp were fed with vegetable diet. Nevertheless, further studies are required to explore how shrimp genetic line-diet interaction influences microbiota for probiotic development and functional food formulation for farmed shrimp according to the genetic line.

\section{Acknowledgments}

This research was financed by the National Council for Science and Technology (CONACYT) through the Cátedras CONACYT Program (Project No. 1037) and the Technological Institute of Sonora through the Program of Promotion of and Support to Research Projects (PROFAPI No. 2020_0005). We thank Dr. Juan Carlos Gil Núñez for providing the dietary treatments.

\section{Authors' Contributions}

Conceptualization: Gonzalez-Galaviz, J.R.; Martinez-Porchas, M.; Casillas-Hernández, R. Data Acquisition: Gonzalez-Galaviz, J.R.; CasillasHernández, R.; Rodriguez-Anaya, L.Z.; MagdalenoMoncayo, D. Data analysis: Martinez-Porchas, M.; Vargas-Albores, F.; Rodriguez-Anaya, L.Z.; Lares-Villa, F. Design of methodology: Gonzalez-Galaviz, J.R; Martinez-Porchas, M. Writing and Editing: GonzalezGalaviz, J.R.; Martinez-Porchas, M.; Vargas-Albores, F.

\section{References}

Association of Official Analytical Chemists - International [AOAC]. 2016. Official Methods of Analysis of AOAC. 19ed. AOAC International, Gaithersburg, MD, USA.

Brestoff, J.R.; Artis, D. 2013. Commensal bacteria at the interface of host metabolism and the immune system. Nature Immunology 14: 676.

Bolyen, E.; Rideout, J.R.; Dillon, M.R.; Bokulich, N.A.; Abnet, C.; Al-Ghalith, G.A.; Bai, Y. 2019. Reproducible, interactive, scalable and extensible microbiome data science using QIIME 2. Nature Biotechnology 37: 852-857.

Brown, R.M.; Wiens, G.D.; Salinas, I. 2019. Analysis of the gut and gill microbiome of resistant and susceptible lines of rainbow trout (Oncorhynchus mykiss). Fish and Shellfish Immunology 86: 497-506.

Callahan, B.J.; McMurdie, P.J.; Rosen, M.J.; Han, A.W.; Johnson, A.J.; Holmes, S.P. 2016. DADA2: high-resolution sample inference from Illumina amplicon data. Nature Methods 13: 581-583.

Caporaso, J.G.; Lauber, C.L.; Walters, W.A.; Berg-Lyons, D.; Lozupone, C.A.; Turnbaugh, P.J.; Fierer, N.; Knight, R. 2011. Global patterns of $16 \mathrm{~S}$ rRNA diversity at a depth of millions of sequences per sample. Proceedings of the National Academy of Sciences of the United States of America 108: 4516-4522.

Castillo-Juárez, H.; Campos-Montes, G.R.: Caballero-Zamora, A.; Montaldo, H.H. 2015. Genetic improvement of Pacific white shrimp [Penaeus (Litopenaeus) vannamei]: perspectives for genomic selection. Frontiers in Genetics 6: 93. 
Chapagain, P.; Arivett, B.; Cleveland, B.M.; Walker, D.M.; Salem, M. 2019. Analysis of the fecal microbiota of fast-and slowgrowing rainbow trout (Oncorhynchus mykiss). BMC Genomics 20: 788 .

Cornejo-Granados, F.; Gallardo-Becerra, L.; Leonardo-Reza, M.; Ochoa-Romo, J.P.; Ochoa-Leyva, A. 2018. A meta-analysis reveals the environmental and host factors shaping the structure and function of the shrimp microbiota. PeerJ 6: e5382.

Cornejo-Granados, F.; Lopez-Zavala, A.A.; Gallardo-Becerra, L.; Mendoza-Vargas, A.; Sánchez, F.; Vichido, R.; Brieba, L.G.; Viana, M.T.; Sotelo-Mundo, R.R.; Ochoa-Leyva, A. 2017. Microbiome of Pacific whiteleg shrimp reveals differential bacterial community composition between Wild, Aquacultured and AHPND/EMS outbreak conditions. Scientific Reports 7: 11783.

Dai, P.; Luan, S.; Lu, X.; Luo, K.; Cao, B.; Meng, X.; Kong, J. 2017. Genetic evaluation of feeding efficiency in the breeding population of Fenneropenaeus chinensis "Huanghai No. 2" using phenotypic, pedigree and genomic information. Aquaculture International 25: 2189-2200.

De Donato, M.; Manrique, R.; Ramirez, R.; Mayer, L.; Howell, C. 2005. Mass selection and inbreeding effects on a cultivated strain of Penaeus (Litopenaeus) vannamei in Venezuela. Aquaculture 247: 159-167.

Desai, A.R.; Links, M.G.; Collins, S.A.; Mansfield, G.S.; Drew, M.D.; Van Kessel, A.G.; Hill, J.E. 2012. Effects of plantbased diets on the distal gut microbiome of rainbow trout (Oncorhynchus mykiss). Aquaculture 350: 134-142.

Duan, Y.; Zhang, Y.; Dong, H.; Wang, Y.; Zheng, X.; Zhang, J. 2017. Effect of dietary Clostridium butyricum on growth, intestine health status and resistance to ammonia stress in Pacific white shrimp Litopenaeus vannamei. Fish and Shellfish Immunology 65: 25-33.

Fan, J.; Chen, L.; Mai, G.; Zhang, H.; Yang, J.; Deng, D.; Ma, Y. 2019. Dynamics of the gut microbiota in developmental stages of Litopenaeus vannamei reveal its association with body weight. Scientific Reports 9: 1-10.

Food and Agriculture Organization of the United Nations [FAO]. 2018. The State of World Fisheries and Aquaculture 2018 Meeting the Sustainable Development Goals. FAO, Rome, Italy. Available at: http://www.fao.org/3/I9540EN/i9540en.pdf

Gao, S.; Pan, L.; Huang, F.; Song, M.; Tian, C.; Zhang, M. 2019. Metagenomic insights into the structure and function of intestinal microbiota of the farmed Pacific white shrimp (Litopenaeus vannamei). Aquaculture 499: 109-118.

Garibay-Valdez, E.; Martínez-Córdova, L.R.; Vargas-Albores, F.; Gollas-Galván, T.; Lago-Leston, A.; Calderón, K.; MartinezPorchas, M. 2019. Biofilm consumption shapes the intestinal microbiota of shrimp (Penaeus vannamei). Aquaculture Nutrition 25: 427-435.

Gitterle, T.; Ødegård, J.; Gjerde, B.; Rye, M.; Salte, R. 2006. Genetic parameters and accuracy of selection for resistance to white spot syndrome virus (WSSV) in Penaeus (Litopenaeus) vannamei using different statistical models. Aquaculture 251: 210-218.

Gitterle, T.; Salte, R.; Gjerde, B.; Cock, J.; Johansen, H.; Salazar, M.; Lozano, C.; Rye, M. 2005. Genetic (co)variation in resistance to White Spot Syndrome Virus (WSSV) and harvest weight in Penaeus (Litopenaeus) vannamei. Aquaculture 246: 139-149.
Gjedrem, T.; Rye, M. 2018. Selection response in fish and shellfish: a review. Reviews in Aquaculture 10: 168-179.

Gong, H.; Jiang, D.; Alig, F.; Lawrence, A.L. 2012. Effects of dietary protein level and source on the growth and survival of two genetic lines of specific-pathogen-free Pacific white shrimp, Penaeus vannamei. Aquaculture 338: 118-123.

Gonzalez-Galaviz, J.R.; Casillas-Hernández, R.; Flores-Perez, M.B.; Lares-Villa, F.; Bórquez-López, R.A.; Gil-Núñez, J.C. 2020. Effect of genotype and protein source on performance of Pacific white shrimp (Litopenaeus vannamei). Italian Journal of Animal Science 19: 289-294.

Huang, Z.; Li, X.; Wang, L.; Shao, Z. 2016. Changes in the intestinal bacterial community during the growth of white shrimp, Litopenaeus vannamei. Aquaculture Research 47: 1737-1746.

Kozich, J.J.; Westcott, S.L.; Baxter, N.T.; Highlander, S.K.; Schloss, P.D. 2013. Development of a dual-index sequencing strategy and curation pipeline for analyzing amplicon sequence data on the MiSeq illumina sequencing platform. Applied and Environmental Microbiology 79: 5112-5120.

Landsman, A.; St-Pierre, B.; Rosales-Leija, M.; Brown, M.; Gibbons, W. 2019. Investigation of the potential effects of host genetics and probiotic treatment on the gut bacterial community composition of aquaculture-raised Pacific whiteleg shrimp, litopenaeus vannamei. Microorganisms 7: 217.

Le, D.; Nguyen, P.; Nguyen, D.; Dierckens, K.; Boon, N.; Lacoere, T.; Bossier, P. 2020. Gut microbiota of migrating wild rabbit fish (Siganus guttatus) larvae have low spatial and temporal variability. Microbial Ecology 79: 539-551.

Li, X.; Yan, Q.; Xie, S.; Hu, W.; Yu, Y.; Hu, Z. 2013. Gut microbiota contributes to the growth of fast-growing transgenic common carp (Cyprinus carpio L.). PLoS One 8: e64577.

Li, F.; Hitch, T.C.; Chen, Y.; Creevey, C.J. 2019. Comparative metagenomic and metatranscriptomic analyses reveal the breed effect on the rumen microbiome and its associations with feed efficiency in beef cattle. Microbiome 7: 6 .

López-Vela, M.; Puente, M.E.; Civera-Cerecedo, R.; ArredondoVega, B.O.; Andreatta, E.R.; Magallón-Barajas, F.J. 2014. Characterization of wastewater generated by Litopenaeus vannamei after being fed experimental diets based on animal protein, vegetable protein and a commercial diet. Aquaculture Research 45: 1921-1931.

Lu, X.; Luan, S.; Luo, K.; Meng, X.; Li, W.; Sui, J.; Cao, B.; Kong, J. 2016. Genetic analysis of the Pacific white shrimp (Litopenaeus vannamei): heterosis and heritability for harvest body weight. Aquaculture Research 47: 3365-3375.

Luan, S.; Luo, K.; Chai, Z.; Cao, B.; Meng, X.; Lu, X.; Liu, N.; $\mathrm{Xu}$, S.; Kong, J. 2015. An analysis of indirect genetic effects on adult body weight of the Pacific white shrimp Litopenaeus vannamei at low rearing density. Genetics Selection Evolution 47: 95.

Mendoza-Cano, F.; Enríquez-Espinoza, T.; Encinas-García, T.; Sánchez-Paz, A. 2014. Prevalence of the infectious hypodermal and hematopoietic necrosis virus in shrimp (Penaeus vannamei) broodstock in northwestern Mexico. Preventive Veterinary Medicine 117: 301-304. 
Naylor, R.L.; Hardy, R.W.; Bureau, D.P.; Chiu, A.; Elliott, M.; Farrell, A.P.; Forster, I.; Gatlin, D.M.; Goldburg, R.J.; Hua, K.; Nichols, P.D. 2009. Feeding aquaculture in an era of finite resources. Proceedings of the National Academy of Sciences of the United States of America 106: 15103-15110.

Ødegård, J.; Gitterle, T.; Madsen, P.; Meuwissen, T.H.; Yazdi, M.H.; Gjerde, B.; Pulgarin, C.; Rye, M. 2011. Quantitative genetics of taura syndrome resistance in pacific white shrimp (Penaeus vannamei): a cure model approach. Genetics Selection Evolution 43: 14.

Parks, D.H.; Tyson, G.W.; Hugenholtz, P.; Beiko, R.G. 2014. STAMP: statistical analysis of taxonomic and functional profiles. Bioinformatics 30: 3123-3124.

Porchas-Cornejo, M.; Martínez-Córdova, L.; Ramos-Trujillo, L.; Hernández-López, J.; Martínez-Porchas, M.; Mendoza-Cano, F. 2011. Effect of promoted natural feed on the production, nutritional, and immunological parameters of Litopenaeus vannamei (Boone, 1931) semi-intensively farmed. Aquaculture Nutrition 17: e622-e628.

Rimoldi, S.; Terova, G.; Ascione, C.; Giannico, R.; Brambilla, F. 2018. Next generation sequencing for gut microbiome characterization in rainbow trout (Oncorhynchus mykiss) fed animal by-product meals as an alternative to fishmeal protein sources. PLoS One 13: e0193652.

Ringø, E.; Zhou, Z.; Vecino, J.L.G.; Wadsworth, S.; Romero, J.; Krogdahl, Å.; Olsen, R.E.; Dimitroglou, A.; Foey, A.; Davies, S.; Owen, M.; Lauzon, H.L.; Martinsen, L.L.; De Schryver, P.; Bossier, P.; Sperstad, S.; Merrifield, D.L. 2016. Effect of dietary components on the gut microbiota of aquatic animals. A neverending story? Aquaculture Nutrition 22: 219-282.

Rungrassamee, W.; Klanchui, A.; Maibunkaew, S.; Chaiyapechara, S.; Jiravanichpaisal, P.; Karoonuthaisiri, N. 2014. Characterization of intestinal bacteria in wild and domesticated adult black tiger shrimp (Penaeus monodon). PloS One 9: e91853.
Serra, C.R.; Almeida, E.M.; Guerreiro, I.; Santos, R.; Merrifield, D.L.; Tavares, F.; Oliva-Teles, A.; Enes, P. 2019. Selection of carbohydrate-active probiotics from the gut of carnivorous fish fed plant-based diets. Scientific Reports 9: 1-15.

Silva, B.C.; Nolasco-Soria, H.; Magallón-Barajas, F.; CiveraCerecedo, R.; Casillas-Hernández, R.; Seiffert, W. 2016. Improved digestion and initial performance of whiteleg shrimp using organic salt supplements. Aquaculture Nutrition 22: 9971005.

Tacon, A.; Cody, J.; Conquest, L.; Divakaran, S.; Forster, I.; Decamp, O. 2002. Effect of culture system on the nutrition and growth performance of Pacific white shrimp Litopenaeus vannamei (Boone) fed different diets. Aquaculture Nutrition 8: 121-137.

Tzuc, J.T.; Escalante, D.R.; Herrera, R.R.; Cortés, G.G.; Ortiz, M.L.A. 2014. Microbiota from Litopenaeus vannamei: digestive tract microbial community of Pacific white shrimp (Litopenaeus vannamei). SpringerPlus 3: 280.

Vargas-Albores, F.; Porchas-Cornejo, M.A.; Martínez-Porchas, M.; Villalpando-Canchola, E.; Gollas-Galván, T.; MartínezCórdova, L.R. 2017. Bacterial biota of shrimp intestine is significantly modified by the use of a probiotic mixture: a high throughput sequencing approach. Helgoland Marine Research 71: 5 .

Wingett, S.W.; Andrews, S. 2018. FastQ Screen: a tool for multigenome mapping and quality control. F1000Res 7: 1338.

Wyban, J.; Walsh, W.A.; Godin, D.M. 1995. Temperature effects on growth, feeding rate and feed conversion of the Pacific white shrimp (Penaeus vannamei). Aquaculture 138: 267-279. 